\title{
Öğrencilerde Eudaimonianın ve Akademik Başarının Yordayıcısı Olarak Ekonomik, Sosyal ve Kültürel Düzey
}

\author{
Umut Birkan ÖZKAN*
}

\begin{abstract}
Öz: Bu çalışmada, 15 yaş grubundaki öğrencilerin ekonomik, sosyal ve kültürel düzeylerinin öğrencilerin eudaimonia düzeyleri ve akademik başarıları üzerindeki yordayıcılığını incelemek amaçlanmaktadır. Bu çalışma, nicel bir araştırma olup PISA-2018 değerlendirmesine ilişkin ikincil veriler analiz edilmiştir. Çalışmanın verileri, PISA-2018'e Türkiye'den katılan 15 yaşındaki 6890 öğrenciden elde edilmiştir. Bu öğrencilerin "eudaimonia indeksleri”, "ekonomik, sosyal ve kültürel düzey indeksleri" ve "matematik, okuma becerileri ve fen puanları" kullanılmıştır. Veriler, IEA International Database Analyzer Version 4.0.35 (IDB Analyzer) yazılımında basit doğrusal regresyon kullanılarak analiz edilmiştir. Araştırma sonuçlarına göre, Türkiye'deki öğrencilerin ekonomik, sosyal ve kültürel düzeylerinin öğrencilerin eudaimonia düzeylerinde herhangi bir değişikliğe yol açmadığı söylenebilir. Bununla birlikte öğrencilerin ekonomik, sosyal ve kültürel düzeylerinin öğrencilerin matematik, okuma becerileri ve fen başarısının önemli bir yordayıcısı olduğu sonucuna varılmıştır. Araştırma sonuçlarına göre, uygulayıcılar ve araştırmacılar için bazı önerilerde bulunulmuştur.
\end{abstract}

Anahtar Sözcükler: Eudaimonia, Akademik Başarı, Matematik Başarısı, Okuma Becerileri Başarısı, Fen Başarısı, Ekonomiksosyal-kültürel Düzey, PISA-2018

\section{Economic, Social, and Cultural Status as Predictors of the Eudaimonia and Academic Success in Students}

\begin{abstract}
This study, to examine the predictive of 15-year-old students' economic, social, and cultural status, as well as eudaimonia levels, and on students' academic achievement. This study uses quantitative research and secondary data related to PISA-2018 evaluation were analyzed. The data of this study was obtained from 6890 students aged 15 in Turkey who attended Programme for International Student Assessment (PISA-2018). These students' eudaimonia indices, economic, social, and cultural status indices, and mathematics, reading skills, and science scores were used. The data were analyzed using simple linear regression in the IEA International Database Analyzer Version 4.0.35 (IDB Analyzer) software. According to the results of the research, economic, social, and cultural status of students in Turkey does not lead to any change in the level of eudaimonia. However, it was concluded that the economic, social, and cultural status of students is a significant predictor of mathematics, reading skills, and science achievement. Finally, some suggestions have been made for practitioners and researchers.
\end{abstract}

Keywords: Eudaimonia, Academic Achievement, Mathematics Achievement, Reading Skills Achievement, Science Achievement, Economic-social-cultural Status, PISA-2018 
Yaşamın anlamını bulmanın ve akademik başarı elde etmenin günümüzde hemen her öğrencinin sahip olmak isteyebileceği iki önemli fenomen olduğu söylenebilir. Yaşamdaki anlam fenomenolojisi; insanın işlevselliği, deneyimleri, bireyselleşmesi, olgunluğu ve potansiyeli üzerine yapılan çalışmalar yoluyla araştııılmıştır (Morgan ve Farsides, 2009). Reker (2000) yaşamın anlamının kişinin varlığında düzen, tutarlılık, amaç bilinci, değerli hedeflerin peşinde koşma, bunlara ulaşma ve beraberinde gerçekleşme duygusu içeren çok boyutlu bir yapı olduğunu ifade etmektedir. Steger, Kashdan, Sullivan ve Lorentz (2008) yaşamdaki anlam arayışını, insanların yaşamlarının anlamını, önemini ve amacını anlamalarını sağlamak ve/veya artırmak arzusunun ve çabalarının gücü, yoğunluğu ve faaliyeti olarak tanımlamaktadır. Bireyin psikolojik ve sosyal açıdan iyi oluşunu da kapsayan yaşamın anlamı, Aristoteles'in görüşlerine dayanan eudaimonia ile kavramsallaştırılmıştır (Gallagher, 2009; Ryff ve Singer, 2008).

Eudaimonia kavramının "ne"liğine ilişkin olarak alanyazında farklı görüşler bulunduğu söylenebilir. Bu konuya dikkat çeken Huta ve Waterman (2014), eudaimonianın kavramsallaştırılmasında akademisyenlerin görüş birliğinin çok az olduğunu belirtmektedir. Eudaimonia kelimesinin etimolojisine bakıldığında Eski Yunancada iyi anlamına gelen $e u$ ile tanrı, ilahi bir güç, ruh, kişinin kaderini etkileyen ruhsal varlık, sahip olduğu özellikler açısından Tanrı ile insan arasında yer alan cisimsiz bir güç, vicdan gibi anlamları içeren daimon kelimesinin birleşmesinden oluşmuş mutlu olarak nitelendirilen eudaimon sıfatının isim hali olduğu görülmektedir (Kalayc1, 2014; Livan, 2016; Omay, 2004). Eudaimonia yerine mutluluk ve psikolojik iyilik hali kavramları sıklıkla kullanılsa da (Kagan, 1992; Kenny, 1999; Waterman, 1993), modern anlamdaki mutluluğun içerdiği memnuniyetle ilişkilendirilen zevk veya fayda gibi tek, monistik bir kavram olarak düşünülmemektedir (Crespo ve Mesurado, 2015). Waterman'a (1990) göre eudaimonia, erdemi anlamlandıran bir eylemdir. Waterman, Schwartz ve Conti (2008), kişinin yaşamın anlamına ve yaşamdaki amaçlarına ulaşması için kendini gerçekleştirme sürecinde var olan duygulara karşılık gelen kavramın eudaimonia olduğunu ileri sürmektedir. Ryff (2019), eudaimonianın kişinin bireysel potansiyelini geliştirme çabası üzerine inşa edilmiş bir tür kişisel mükemmellik ve anlam arayışı olduğunu savunmaktadır. Eudaimonia farklı şekillerde kavramsallaştırılsa da bu konudaki ortak düşüncenin; erdemli bir yaşam için insanın yaşadığı günlük ve geçici mutluluktan öte bir anlam arayışı olduğu söylenebilir.

Eudaimonik bireylerin yaşamlarındaki anlamı bulmak için diğerlerinden farklılık gösteren bazı tutumlara sahip oldukları ve davranışlar sergiledikleri söylenebilir (Gülcan ve Nedim-Bal, 2014; Ryan ve Deci, 2001; Ryff, 1995). Ryan ve Deci'ye (2001) göre eudaimonik bireyler kim olduklarının ayırtına varıp gizilgüçlerini geliştirir, yaşamını anlamlı hale getirecek eylemlerde bulunur ve anlam atfettiği yaşam amacını gerçekleştirmek için çaba sarf ederler. Ryff (1995) de eudaimonia arayışında olan bireylerin öz-kabul, çevresini yönetmede ustalık, özerklik, başkalarıyla olumlu ilişkiler geliştirme, anlamlı ve amaçlı bir yaşam ve sürekli gelişim duygularına sahip olduklarını belirtmektedir. Tüm bunlara ilave olarak, eudaimonia düzeyi yüksek olan bireylerin, kendisindeki ve çevresindeki gelişme ve değişmelere ilgi duyduğu ve olumlu bir öğrenme isteğine sahip olduğu ifade edilebilir (Gülcan ve Nedim-Bal, 2014). Bununla birlikte güçlü eudaimoniaya sahip bireyler optimal öğrenenlerdir ve aidiyet duyguları gelişmiştir (Organisation for Economic Co-operation and Development [OECD], 2019a). Bunların tümü birlikte düşünüldüğünde, eudaimonia yönelimli bireylerin eğitim yoluyla kazandırılmak istenen birçok olumlu tutum ve davranışı yaşamlarının anlamını bulma doğrultusunda işe koştukları ifade edilebilir.

Bu çalışmanın iki odak noktasından biri yaşamın anlamı bağlamında eudaimoniadır. Ryan, Huta ve Deci (2008) yaşamın anlamını ve amacını diğer bir ifadeyle eudaimoniayı neyin oluşturduğunu ve neyin teşvik ettiğini incelemenin, eski felsefelerin kritik bir parçası olduğu gibi, çă̆daş davranış bilimindeki en önemli gündemler arasında olduğunu belirtmektedir. Eudaimonia ile ilgili yapılmış çeşitli ölçek ve anket çalışmaları vardır (Diener ve diğerleri, 2010; Peterson, Park ve Seligman, 2005; Reker, 1996; Ryff, 1989; Waterman ve diğerleri, 2010). Öğrencilerin eudaimonia düzeylerinin belirlenmesine yer veren çalışmalardan biri, OECD'nin Uluslararası Öğrenci Değerlendirme Programı (Programme for International Student Assessment [PISA])'dır. Güçlü bir eudaimoniaya sahip bireylerin ideal öğrenenler olduğuna ve bu kişilerin aidiyet duygularının geliştiğine vurgu yapılan PISA'da (OECD, 2019a), öğrencilerin eudaimonia düzeylerini belirlemeye yönelik sorular sorularak her bir öğrenci için eudaimonia indeksi hesaplanmaktadır. 
$\mathrm{Bu}$ araştırmanın bir diğer odak noktası ise öğrencilerin akademik başarısıdır. Başarı; notlara, derecelere ve devlet onayının veya belgelendirmesinin farklı formlarına yansıtılabilecek bilgi, yetkinlik ve daha üst düzey statüye erişim olarak tanımlanabilir (Collins ve O'Brien, 2003). Akademik başarı, öğrencinin, öğretmenin, eğitim programının ve eğitim kurumunun önceden belirlenmiş eğitim hedeflerine ne ölçüde ulaştı̆̆ını gösterir (Kpolovie, Joe ve Okoto, 2014). Akademik başarı, öğrencilerin ders notları veya genel not ortalaması gibi akademik çalışmalarının kalitesini gösteren bir sonuç olarak değerlendirilebilir (York, Gibson ve Rankin, 2015). Öğretmenlerce takdir edilen notların dişında standart başarı testleri de akademik başarıyı belirlemede bir ölçüt olarak kullanılmaktadır (Kenç ve Oktay, 2002). PISA'da öğrencilere çeşitli alanlarda uygulanan başarı testlerinin de bu grupta yer aldığı söylenebilir. Son olarak 2018 yılında yapılan ve Türkiye'nin de katıldığı PISA çalışmasında matematik, okuma becerileri ve fen alanlarında öğrenciler değerlendirilmiştir.

Araştırmacılar, eudaimonianın sosyokültürel bağlamlarda değiştiğini, kültürel normlardan etkilendiğini ileri sürmektedirler (Khumalo, Temane ve Wissing, 2012; Ryff ve Singer, 1998; Sokoya, Muthukrishna ve Collings, 2005). Khumalo ve diğerlerinin (2012) araştırma bulguları, sosyodemografik değişkenlerin Güney Afrika'daki Setswana konuşan bir toplulukta eudaimonianın belirlenmesinde rol oynadığını göstermektedir. Ryff ve Singer (1998) ise eudaimonianın kültürel formlardan etkilendiğini, Afrika'da yaşamın anlamının başkalarına ve sosyal düzene karşı yükümlülükleri içerebilirken Doğu'daki (Kore) ve Batı'daki (Amerika Birleşik Devletleri $[\mathrm{ABD}])$ orta yaş grubu yetişkinlerin eudaimoniayı değerlendirmede yaşamdaki amaca vurgu yaptığını belirtmektedir. Sokoya ve diğerleri (2005), Nijerya'nın güney batısındaki baskın etnik grup olan Yorubas'lı 40 yetişkin (17 erkek ve 23 kadın) ve 31 çocuk (17 erkek ve 14 kadın) katılımcıyla gerçekleştirdikleri çalışmada kültürel faktörlerin eudaimoniayı etkilediğini ortaya koymaktadır. Bununla birlikte alanyazında sosyoekonomik faktörlerin eudaimonia ile ilişkisini ortaya koyan araştırmalar da yer almaktadır (Klein, 2019; Mackenzie, Karaoylas ve Starzyk, 2018; Ryan ve Martela, 2016; Vanhoutte ve Nazroo, 2016). Klein'in (2019) araştırmasının sonuçları ekonomik özgürlüğün eudaimonia ile pozitif ilişkili olduğunu göstermektedir. Mackenzie ve diğerlerinin (2018) yaş ve eudaimonia arasındaki ilişkiyi araştırdığı çalışmasında, yaş ve eudaimonia arasındaki ilişkinin evrensel olmadığını ve sosyal, kültürel ve ekonomik koşullardan etkilendiği bulunmuştur. Ryan ve Martela (2016) da çalışmalarında, sosyoekonomik koşulların eudaimoniayı etkilediğini öne süren yeni kanıtlar sunmaktadır. Vanhoutte ve Nazroo'nun (2016), mütevazi bir aileden gelmeye kıyasla, yüksek sosyoekonomik bir pozisyonda büyümenin ABD'deki yetişkinlerin eudemoniaları üzerinde pozitif yönde güçlü bir etkisi olduğunu raporlamışlardır.

Bazı araştırmacılar ise akademik başarının ekonomik, sosyal ve kültürel faktörlerden etkilendiğini savunmaktadırlar (Aslanargun, Bozkurt, ve Sarıŏlu, 2016; Bourdieu, 1996; Çiftçi ve Çağlar, 2014; Karaağaç, 2019; Yolsal, 2016). Aslanargun ve diğerlerinin (2016) 6, 7 ve 8. sinıflarda öğrenim gören 691 öğrenci üzerinde yürüttüğü çalışmada, not ortalamaları ile aile geliri, baba mesleği, ebeveyn eğitim düzeyi arasında anlamlı bir fark olduğu bulunmuştur. Çiftçi ve Çağlar'ın (2014) aile özelliklerinin öğrencilerin üniversiteye giriş sınavı başarıları üzerindeki etkisini analiz ettikleri çalışmanın sonuçları, evdeki kitap sayısı, cep telefonu sahipliği, dershaneye gidebilme, ebeveyn eğitim düzeyi değişkenlerinin akademik başarı üzerinde anlamlı bir etkisi bulunduğunu göstermektedir. Karaağaç'ın (2019) öğrencilerin ekonomik, sosyal ve kültürel statü özelliklerinin ortaöğretime geçiş sınavında gösterdikleri başarı üzerindeki etkisini inceleyen araştırmasının sonuçları, öğrencilerin puanları ile ekonomik, sosyal ve kültürel düzey indeksleri arasında güçlü bir ilişki bulunduğunu işaret etmektedir. Yolsal'ın (2016) PISA-2012 verilerini kullandığı çalışmada, öğrencilerin sosyoekonomik ve kültürel statülerinin öğrencilerin akademik başarısı üzerinde istatistiksel olarak anlamlı bir etkisi olduğu belirlenmiştir. Benzer görüşleri dile getiren Bourdieu (1996, s.105), "belirli bir anda elde edilen eğitim sermayesinin mensup olunan ailenin ekonomik ve sosyal seviyesini ifade ettiğini" çünkü "sosyal kökenin, nitelikleri aynı olan bireyleri ayırt edebileceğini" öne sürmektedir.

Ekonomik, sosyal ve kültürel düzeyin eudaimonia ve akademik başarı ile olan ilişkisini ortaya koyan bu araştırmalar birbirinden bağımsız ve farklı yapıda veri setlerinin kullanıldığı analizlerin bulgularını sunan çalışmalardır. Diğer bir ifadeyle, farklı örneklem grupları için elde edilen ekonomik, sosyal ve kültürel değişkenlere ilişkin veriler ile öğrencilerin ya da yetişkinlerin eudaimonia düzeyleri ve farklı öğrenci 
gruplarının akademik başarıları arasındaki ilişkilerin ya da yordayıcılıkların ayrı ayrı incelendiği söylenebilir. $\mathrm{Bu}$ çalışmada ise öğrencilerin eudaimonia ve akademik başarı düzeylerinin değerlendirildiği PISA-2018'de öğrencinin ailesinin eğitim seviyesi, mesleki statüsü gibi değişkenlerden oluşturulan (OECD, 2019b) ekonomik, sosyal ve kültürel düzey indeksi kullanılmaktadır. Bu sayede, aynı örneklem grubu için hesaplanan ekonomik, kültürel ve sosyal düzey değişkeninin örneklem grubu değişmeksizin aynı katılımcıların eudaimonia ve akademik başarıları üzerindeki belirleyiciliğinin incelenmesi mümkün hale getirilmektedir.

Bu çalışmanın sonuçlarının özellikle eğitim alanındaki uygulayıcılar ve politika yapıcılar için önemli bilimsel kanıtlar sağlayabileceği düşünülmektedir. Kökleri Aristoteles'e dayanan eudaimonianın öğrencilerin ekonomik, sosyal ve kültürel düzeyleri açısından incelenmesinin eğitimin psikolojik süreçleri üzerinde uygulamalar yapan ve politikalar üretenlere anlamlı katkıları olabilir. Aristoteles'in eudaimoniasının günümüz Türkiye'sindeki öğrencilerin ekonomik, sosyal ve kültürel düzeyleri bağlamında ifade ettiği anlamin güncel, geniş ve güvenilir bir veri seti kullanarak sorgulanması sonucu değerli bulgulara ulaşılabileceği düşünülmektedir. Ergenlik dönemine rastlayan, stres ve kaygı yaratan koşullarla karşı karşıya kalınan, kişilik ediniminin gerçekleştiği, depresyonun, ani karar değişiklikleri ya da kararsızlıkların görülebildiği öğrencilik dönemlerinde (Ehtiyar, Ersoy, Akgün ve Karapınar, 2017), öğrencilerin olumlu yöndeki gelişimleri, yetişkinliğe kadar devam edebilecek sağlık durumları ve davranış kalıpları ile ilişkili olan eudaimonianın (OECD, 2019b) belirleyicilerinin araştırılması, öğrencilerin yaşamlarındaki anlamı yakalayabilmeleri açısından oldukça önemli olabilir. Bununla birlikte eudaimonia üzerinde öğrencilerin ekonomik, sosyal ve kültürel düzeylerinin yordayıcılığının incelenmesinin, öğrencilerin eudaimonia düzeyleri üzerinde etkili olan faktörleri çalışmak isteyen araştırmacılar için de ilgi çekici bir konu olma özelliği taşıyabilir.

Bunun yanı sıra, alanyazında PISA-2018 çerçevesinde değerlendirilen ekonomik, sosyal ve kültürel düzey ile öğrencilerin eudaimonia düzeyleri ve akademik başarıları arasındaki ilişkiyi aynı çalışma kapsamında inceleyen herhangi bir araştırmaya rastlanmamaktadır. Bu bakış açısıyla değerlendirildiğinde araştırmanın önemli bir katkısının, öğrencilerin ekonomik, sosyal ve kültürel düzeylerinin öğrencilerin eudaimonia düzeyleri ve akademik başarıları üzerindeki etkisinin bir arada görülerek karşılaştırma ve çıkarım yapmayı sağlayan bulgular içermesi olduğu söylenebilir.

Öte yandan, araştırma örneklemini Türkiye'deki 15 yaş grubu öğrencileri oluşturmaktadır. Bu çağ nüfusunun yaşamdaki anlam ve amaç arayışının ve akademik başarılarının belirleyicilerinin iyi anlaşılması Türkiye açısından oldukça önemlidir. Geleceğin yetişkinleri olacak bu öğrencilerin eudaimonialarında ve akademik başarılarında ekonomik, sosyal ve kültürel düzeylerinin etkisinin incelenmesi, mutlu ve amaçlı bir Türkiye açısından da oldukça önemli görülmektedir.

Bu çalışmada, 15 yaş grubundaki öğrencilerin ekonomik, sosyal ve kültürel düzeylerinin öğrencilerin eudaimonia düzeyleri ve akademik başarıları üzerindeki yordayıcılığını incelemek amaçlanmaktadır. Çalı̧̧mada ilk olarak, öğrencilerin eudaimonia düzeyleri üzerinde ekonomik, kültürel ve sosyal düzeylerinin belirleyici olup olmadığına bakılacaktır. Sonrasında ise öğrencilerin akademik başarıları üzerinde öğrencilerin ekonomik, kültürel ve sosyal düzeylerinin yordayıcılıkları incelenecektir. Bu amaç doğrultusunda cevap aranan sorular şunlardır:

1. Türkiye'deki 15 yaş grubu öğrencilerin eudaimonia düzeylerinin yordanmasında ekonomik, sosyal ve kültürel düzeylerinin rolü nedir?

2. Türkiye'deki 15 yaş grubu öğrencilerin ekonomik, sosyal ve kültürel düzeyleri öğrencilerin matematik, okuma becerileri ve fen başarısının anlamlı bir yordayıcısı mıdır?

\section{Yöntem}

Bu çalışma, nicel bir araştırma olup PISA-2018 değerlendirmesine ilişkin ikincil veriler analiz edilmiştir. İkincil veri analizinin, birincil verilerin kullanıldığı çalışmalardaki temel araştırma prensiplerine bağlı kalınması gerekli olan basamakların takip edildiği bir araştırma yöntemi olduğu söylenebilir (Johnston, 2017). Bu yöntemle, özgün araştırma sorularına farklı araştırma yöntemleriyle yanıt bulmak veya eski verilerle yeni 
soruları yanıtlanmak için mevcut bir veri tabanının analizi yapılır (Turner, 1997). Bununla birlikte orijinal analiz bulgularına dayanak sağlamak veya bu bulguları genişletmek için de ikincil veriler kullanabilir (McGinn, 2008). İkincil verilerin kullanıldığ1 çalışmaların, orijinal araştırmada yer verilmeyen yeni ve/veya ilave bulgulara ulaşmaya olanak vermesi (Sherif, 2018) söz konusu yöntemin bu araştırmada tercih edilme sebebi olmuştur.

\section{Örneklem}

Bu çalışmanın verileri, PISA-2018 değerlendirmesine katılan Türkiye'deki 15 yaş çağındaki öğrencileri içeren hedef nüfustan elde edilmiştir. Öğrenci örneklemi, Türkiye'deki 15 yaşındaki öğrencilerin tam hedef nüfusunun temsilini sağlayacak şekilde ve PISA ile ilgili kalite standartları korunarak ulusal proje yöneticileri tarafından kararlaştırılmıştır (örneklem yöntemi hakkında daha fazla bilgi için, bkz. https://www.oecd.org/pisa/data/pisa2018technicalreport/). PISA-2018 örneklem tasarımı, her ülke için iki aşamalı bir tabakalı örneklem tasarımıdır. İlk aşamada, okulun yeri ve eğitim düzeyi (ortaokul veya lise) gibi faktörler dikkate alınarak en az 150 okul örneği seçilmiştir, ikinci aşamada ise bu okullardan 15 yaşındaki yaklaşık 42 öğrenci seçilmiştir (OECD, 2019c). Türkiye'yi temsil eden örneklem kümesine ilişkin sayılar Tablo 1 'de sunulmuştur.

Tablo I

Çalışmanın Örneklemi

\begin{tabular}{lccc}
\hline Ülke & Genel & Eudaimonia indeksi hesaplanan & Başarı puanı hesaplanan \\
\hline Türkiye & 6890 & 6748 & 6855 \\
\hline
\end{tabular}

Tablo 1'e bakıldığında öğrencilerden bazılarının eudaimonia indekslerinin ve akademik başarı puanlarının hesaplanamaması nedeniyle 6890 öğrencinin tamamının araştırmaya dâhil edilemediği görülmektedir. Araştırma dışında kalan öğrencilerin verilerinin örneklemdeki diğer öğrencilerin değerleriyle ilişkili olmaması ve bu durumun örneklemdeki tüm öğrenciler için anlamlı olması nedeniyle araştırmaya dahil edilen grup, örneklemin basit seçkisiz bir örneklemi olarak kabul edilebilir (Allison, 2002).

\section{Veri Toplama Araçları}

Bu çalışmanın verileri PISA-2018 çalışmasına Türkiye'den katılan öğrencilerin öğrenci anketi soruları ile matematik, okuma becerileri ve fen testlerine verdikleri cevaplardan elde edilmiştir. PISA-2018' de çalışmanın bağımlı değişkenlerinden biri olan öğrencilerin eudaimonia düzeylerini belirlemek için 3 maddeden oluşan ve "Kesinlikle Katılmıyorum", "Katılmıyorum", "Katılıyorum" ve "Kesinlikle Katılıyorum" seçeneklerinin bulunduğu dörtlü Likert tipi bir ölçme aracı ile öğrencilerin eudaimonia indeksleri (EUDMO) oluşturulmuştur (OECD 2019a, 2019b). Eudaimonia indekslerini oluşturmak için, "Hayatımın belirgin bir anlamı ve amacı vardır.", "Hayatta beni tatmin edecek bir anlam buldum." ve "Hayatıma neyin anlam vereceği konusunda net bir fikrim var." ifadelerine öğrencilerin ne ölçüde katıldıklarını ("Kesinlikle Katılmıyorum", "Katılmıyorum”, "Katılıyorum", "Kesinlikle Katılıyorum") bildirmeleri istenmiştir. Pozitif indeks değerleri, öğrencilerin eudaimonia düzeylerinin OECD ülke ortalamasından yüksek olduğunu göstermektedir (OECD 2019b). PISA 2018 raporunda, eudaimonia ölçek güvenirliğinde kullanılan Cronbach's $\alpha$ değerinin Türkiye için .83 olduğu belirtilmektedir (OECD, 2019b). Bu değerin iç tutarlılık için iyi bir değer olduğu söylenebilir (Hajjar, 2018; Streiner, 2003). Yapılan faktör analizinde ise üç maddenin aynı faktör altında toplandığı ve toplam varyansın \%73.78' ini (Kaiser-Meyer-Olkin Testi=.706 ve Bartlett Testi=.000) açıladığı bulunmuştur.

Çalışmanın diğer bağımlı değişkenleri olan matematik, okuma becerileri ve fen okuryazarlığının bir göstergesi olarak PISA-2018'de her katılımcı öğrenci için on adet olası değer belirlemiştir. Olası değer metodolojisi, yeterlilik dağılımlarını kullanır ve belirsizliğin sıfır olduğunu varsaymak yerine, birden çok emsalli yeterlilik değerleri kullanarak bireysel düzeyde hatayı hesaba katar (OECD, 2017). Dolayısıyla her öğrenci için birbirinden bağımsız on olası değer kestirimi yapılmaktadır. Bu 10 puandan herhangi birinin kullanılması ya da bu 10 puanın ortalamasının kullanılması standart hatanın normalden daha küçük çıkmasına neden olabilir (Rutkowski, Gonzalez, Joncas ve von Davier, 2010). OECD (2009) de PISA verileri kullanılan çalışmalarda her öğrenci için bu olası değerlerin hepsinin kullanılmasını önermektedir. Açıklanan nedenlerden dolayı bu çalışmada, olası değerlerin tamamı analizlere dahil edilmiştir. 
Çalışmanın bağımsız değişkenleri öğrencilerin ekonomik, sosyal ve kültürel düzey indeksleridir. Ekonomik, sosyal ve kültürel düzey indeksi, öğrencinin ailesine ilişkin sorulan sorulara alınan cevaplardan elde edilen üç değişkenden türetilmiştir. Bu üç değişken, ebeveynin en yüksek eğitim seviyesi, ebeveynin en yüksek mesleki statüsü ve kitaplar da dâhil olmak üzere evdeki eşyalardır (OECD, 2019c). Ebeveynlerin en yüksek eğitim seviyesi değişkeni ile ilgili olarak öğrencilere; “Anneniz, aşağıdaki eğitim kademelerinden en son hangisini bitirmiştir?", "Anneniz aşağıdaki diplomalardan herhangi birine sahip midir?", "Babanız, aşağıdaki eğitim kademelerinden en son hangisini bitirmiştir?", "Babanız aşağıdaki diplomalardan herhangi birine sahip midir?" soruları yöneltilerek uygun cevabı vermeleri istenmektedir (OECD, 2019b). Ebeveynin en yüksek mesleki statüsü değişkeni, öğrencinin anne ve babasının mesleki verilerinin öğrencilerin açı uçlu sorulara verdiği yanttlardan elde edilmektedir (OECD, 2019b). Bu sorular; "Annenizin esas mesleği nedir?", "Anneniz esas mesleğinde hangi işi yapıyor?", "Babanızın esas mesleği nedir?", "Babanız esas mesleğinde hangi işi yapıyor?" açık uçlu sorularıdır. Yanıtlar dört haneli mesleklerin uluslararası standart sınıflandırması (International Standart Classification of Occupations [ISCO]) kodlariyla kodlanmakta ve daha sonra uluslararası sosyoekonomik meslek statüsü endeksi (International Socio-Economic Index of Occupational Status [ISEI]) ile eşleştirilmektedir (OECD, 2019b). Ekonomik, sosyal ve kültürel düzey indeksinin hesaplanmasında kullanılan üçüncü değişken olan evdeki eşyalara ilişkin öğrencilerden üç farklı kategorideki eşyalardan seçimler yapmaları istenmektedir. Bu kategorilerden birincisinde "Evinizde aşağıdakilerden hangileri bulunmaktadır?" sorusuna karşılık olarak; çalışma masası, kendinize ait oda, çalışmak için sessiz bir yer, okul çalışmaları için kullanabileceğiniz bir bilgisayar, eğitim yazılımı, internet bağlantısı, edebiyat klasikleri, şiir kitapları, sanat eserleri (ör. tablolar), okul çalışmaları için kaynak kitaplar, teknik içerikli kitaplar (ör. bilgisayar kitapları), sözlük, müzik, sanat veya tasarım konulu kitaplar, klima tipi ısıtma-soğutma sistemi, ücretli TV abonelikleri, yılda en az bir hafta tatil yapmak (memleket dışında otel vb. yerlerde kalarak yapılan tatiller) seçenekleri öğrencilere sunulmaktadır. İkinci kategoride, "Evinizde aşağıdakilerden kaç tane bulunmaktadır?" sorusu öğrencilere yöneltilerek televizyon, araba, banyolu ya da duşlu oda, internet erişimi olan cep telefonu, bilgisayar, tablet bilgisayarlar, elektronik kitap okuyucular, müzik aletine karşılık "Hiç", "Bir", "İki", "Üç ya da daha fazla" şıklarını seçmeleri istenmektedir. Üçüncü kategoride ise "Evinizde kaç tane kitap bulunmaktadır?" sorusu yöneltilen öğrenciler kendilerine uygun olan sayı aralığını işaretlemektedirler. PISA 2018'de, ekonomik, sosyal ve kültürel düzey indeksi, imputasyon (üç bileşenden birinde veri bulunmayan öğrenciler için diğer iki değişken üzerindeki regresyon ile üçüncü diğer bir ifadeyle eksik değişkeni tahmin etmek, birden fazla bileşende eksik veri varsa indeks değerini hesaplamamak) ve standartlaştırmadan sonra üç değişkenin aritmetik ortalaması alınarak oluşturulmaktadır (OECD, 2019b).

\section{Verilerin Analizi}

Bu çalışmada, Türkiye'deki öğrencilerin eudaimonia düzeyleri ve akademik başarıları üzerinde öğrencilerin ekonomik, sosyal ve kültürel düzeylerinin belirleyiciliği analiz edilmiştir. Bu kapsamda, bağımlı değişken olarak öğrencilerin eudaimonia düzeyleri ve akademik başarı puanları, bağımsız değişken olarak öğrencilerin ekonomik, sosyal ve kültürel düzey indeksleri kullanılarak basit doğrusal regresyon analizleri yapılmıştır.

Analizleri yapmak için IEA International Database Analyzer Version 4.0.35 (IDB Analyzer) yazılımı kullanılmıştır. IDB Analyzer, büyük ölçekli değerlendirmeleri analiz etmek için geliştirilmiştir. IDB Analyzer, örneklem tasarımı ve örneklem ağırlıklarını dikkate alarak istatistiksel analizleri gerçekleştirebilmektedir. PISA'nın kendine has yapısını dikkate alan IDB Analyzer, bağımlı değişkeni yordayan bağımsız değişkenler için çoklu doğrusal regresyon analizini yapabilmekte ve regresyon katsayılarını hesaplayabilmektedir. Bu nedenle, büyük ölçekli değerlendirme verileri kullanılan bu çalışmada güvenilir sonuçlar elde etmek için IDB Analyzer kullanılmıştır.

IDB Analyzer örneklem tasarımını yansıtan katsayıları ve örnekleme hatalarını tahmin etmek için uygun araçlar sağlamakta olup basit doğrusal regresyon için normallik varsayımının doğrulanması gerektiği söylenebilir (Mirazchiyski, 2014). Bu çalışmada yedi bine yakın katılımcının verileri analiz edildiğinden dağılımın normal olduğu kabul edilebilir. Lumley, Diehr, Emerson ve Chen'in (2002) çalışması, yeterince büyük örneklemlerde normal dağılım varsayımının gerekmediğini göstermektedir. Bununla birlikte büyük 
örneklemler için "Büyük Sayılar Yasası" ve "Merkezi Limit Teoremi" mekanizmalarının her ikisi de işe yaramaktadır. Çünkü çok sayıda gözlemin örnek ortalaması, ortalamaya yakın olacak veya gözlemlerin kendileri normal dağılıma sahip olmasa bile, normale yakın bir dağılım gösterecektir (Shatskikh ve Melkumova, 2016).

\section{Bulgular}

İlk araştırma sorusu Türkiye'deki 15 yaş grubu öğrencilerin eudaimonia düzeylerinin yordanmasında ekonomik, sosyal ve kültürel düzeylerinin rolünü belirlemeyi amaçlamaktadır. Bu araştırma sorusunu cevaplamak için yapılan basit doğrusal regresyon analizinin model özeti ve regresyon katsayılarının sonuçları Tablo 2'de verilmektedir.

Tablo II

Öğrencilerin Eudaimonia Düzeyleri için Yapılan Regresyon Analizi Model Özeti ve Regresyon Katsaylları

\begin{tabular}{|c|c|c|c|c|}
\hline \multirow{3}{*}{ Model } & $\begin{array}{l}R^{2}=.0 \\
\text { Düze } \\
\text { Tahm }\end{array}$ & $\begin{array}{l}0 \\
0 \\
\operatorname{tas} 1=.00\end{array}$ & \multirow{3}{*}{$\begin{array}{c}\text { Standartlaştırılmış } \\
\text { Katsayılar } \\
\text { Beta }(\beta)\end{array}$} & \multirow[b]{3}{*}{$\mathrm{t}$} \\
\hline & Standartla & Katsayılar & & \\
\hline & $\mathrm{B}$ & Std. Hata & & \\
\hline $\begin{array}{l}\text { (Sabit Terim) } \\
\text { (a) }\end{array}$ & .19 & .02 & & $9.77^{*}$ \\
\hline Ekonomik, sosyal ve kültürel düzey & .03 & .01 & .03 & $2.74^{*}$ \\
\hline
\end{tabular}

*0.01 düzeyinde anlamlıdır.

Tablo 2'de sunulan basit doğrusal regresyon analiz sonuçları, öğrencilerin ekonomik, sosyal ve kültürel düzey değişkeninin eudaimonia düzeylerindeki varyansı açıklamada herhangi bir katkısının olmadığını $\left(R^{2}=.00\right)$ ortaya koymaktadır. Bununla birlikte Tablo 2 'deki regresyon katsayıları, öğrencilerin ekonomik, kültürel ve sosyal düzeylerinin eudaimonia düzeylerinde oldukça düşük düzeyde bir artış (.03) meydana getirebileceğini göstermektedir.

İkinci araştırma sorusu, Türkiye'deki 15 yaş grubu öğrencilerinin matematik, okuma becerileri ve fen başarısının yordanmasında ekonomik, kültürel ve sosyal düzeylerinin rolünü belirlemeyi amaçlamaktadır. Bu araştırma sorusunu cevaplamak için yapılan basit doğrusal regresyon analizinin model özetleri ve regresyon katsayılarının sonuçları ise Tablo 3'te verilmektedir.

Tablo III

Öğrencilerin Matematik, Okuma Becerileri ve Fen Başarıları için Yapılan Regresyon Analizi Model Özeti ve Regresyon Katsayıları

Matematik Başarısı: $R^{2}=.11$, Düzeltilmiş $R^{2}=.11$, Tahminin Std. Hatası $=.02$

Okuma Becerileri Başarısı: $R^{2}=.11$, Düzeltilmiş $R^{2}=.11$, Tahminin Std. Hatasi $=.02$

Model

Fen Başarısı: $R^{2}=.11$, Düzeltilmiş $R^{2}=.11$, Tahminin Std. Hatası=.02

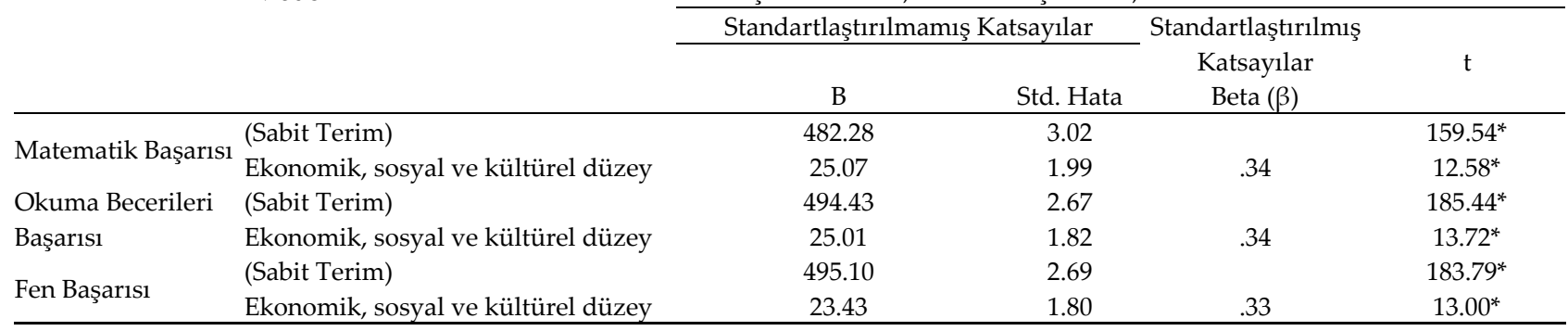

*0.01 düzeyinde anlamlıdır.

Tablo 3 'te sunulan basit doğrusal regresyon analiz sonuçları, öğrencilerin ekonomik, sosyal ve kültürel düzey değişkeninin matematik, okuma becerileri ve fen başarısı puanlarındaki varyansın \%11'ini $\left(\mathrm{R}^{2}=.11\right)$ açıkladığını ortaya koymuştur. Tablo 3'e göre ekonomik, sosyal ve kültürel düzeyin yordayıcılığı istatistiksel olarak anlamlıdır. Bununla birlikte Tablo 3'te sunulan regresyon katsayıları, öğrencilerin ekonomik, sosyal ve

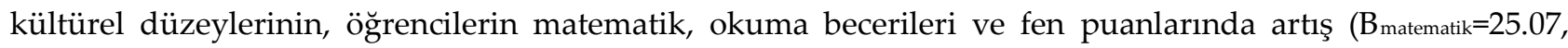
$\mathrm{B}_{\text {okuma }}=25.01, \mathrm{~B}_{\text {fen }}=23.43$ ) meydana getirebileceğini göstermektedir. 
Öğrencilerde Eudaimonianın ve Akademik Başarının...

\section{Sonuç ve Tartışma}

Bu çalışmada ilk olarak Türkiye'deki 15 yaş grubu öğrencilerin eudaimonia düzeylerinin yordanmasında ekonomik, kültürel ve sosyal düzeylerinin rolü incelenmiştir. Basit doğrusal regresyon analizi sonuçları, öğrencilerin ekonomik, sosyal ve kültürel düzeyleri ile eudaimonia düzeyleri arasında herhangi bir ilişki olmadığını $\left(\mathrm{R}^{2}=.00\right)$ göstermektedir. Bu sonuç, alanyazındaki bazı çalışmalar (Biswas-Diener ve Tamir, 2004; Cenkseven-Önder ve Sarı, 2009) ile benzerlik gösterirken bazı çalışmaların (Amato ve Zuo, 1992; Kasser ve Ryan, 1993; Khumalo ve diğerleri, 2012; Lyubomirsky, King ve Diener, 2005; Myers ve Diener, 1995) sonuçları ile tutarlı değildir. Ekonomik, sosyal ve kültürel düzey ve eudaimonia ile ilgili bulgulardaki tutarsızlık, büyük olasılıkla yapıların tanımlanma şekli, kullanılan ölçüm araçları, çalışma örneklemi, demografik koşullar ve toplumsal bağlamın yanı sıra analiz yöntemlerinden kaynaklanıyor olabilir. Küreselleşmenin ve tüketim odaklı ekonomik yapıların eudaimonia düzeylerinde bir artışa neden olmaksızın maddi varlıklarda zenginleşmeye yol açtı̆̆ (Clark, Frijters ve Shields, 2008; Kasser, Cohn, Kanner ve Ryan, 2007) düşünüldügünde, küresel ve tüketici ekonomik yapıyı benimsemiş bir topluma sahip olan Türkiye'deki (The Global Council for Happiness and Wellbeing, 2019) öğrencilerin eudaimonia düzeylerinde ekonomik, sosyal ve kültürel düzeyin anlamlı bir yordayıcı olmamasının anlaşılabilir bir durum olduğu öne sürülebilir. Bununla birlikte özellikle ekonomik, sosyal ve kültürel açıdan iyi düzeyde olan aileler, çocuklarına daha iyi olanaklar ve seçim serbestliği sağlarken, aynı zamanda hayatta neyin peşinde koşmanın iyi ve neyin değerli olduğu sorusunu açık bırakması, öğrencilerde eudaimonia konusunda bir boşluğa neden olabilir (Ryan ve Deci 2001; Waterman 2013). Ayrıca, Ryan ve Martela'nın (2016) öne sürdüğü gibi öğrenciler maddiyata dayalı bir yaşamda aradıklarını bulamayıp maddiyat odaklı mutluluğun ötesinde bir yaşam anlamı ve amacı arıyor olabilirler. Bu çalışmanın bulgularını destekleyen bu görüşlerin ışığında, Türkiye'de PISA-2018'e katılan öğrencilerin eudaimonia düzeylerinde, ekonomik, sosyal ve kültürel düzeyin herhangi bir değişime yol açmadığı söylenebilir.

İkinci olarak, Türkiye'deki 15 yaş grubu öğrencilerin ekonomik, sosyal ve kültürel düzeyleri öğrencilerin matematik, okuma becerileri ve fen başarısının anlamlı bir yordayıcısı olup olmadığı incelenmiştir. Basit doğrusal regresyon analizi sonuçları, öğrencilerin ekonomik, sosyal ve kültürel düzeylerinin matematik, okuma becerileri ve fen başarısının anlamlı bir yordayıcısı olduğunu ortaya koymuştur (Tablo 3). Araştırmanın bu sonucu alanyazındaki diğer çalışmaların sonuçlarıyla benzerlik göstermektedir (Aslanargun ve diğerleri, 2016; Çiftçi ve Çağlar, 2014; Kılıç ve Haşıloğlu, 2017; Özkan, 2018). Aslanargun ve diğerlerinin (2016) araştırmasında, öğrencilerin akademik başarı puanlarının anne ve baba eğitim durumuna göre anlamlı farklılık gösterdiğini, öğrencilerin akademik başarıları ile gelir arasında pozitif ve anlamlı bir ilişki olduğunu bulmuştur. Çiftçi ve Çağlar (2014), sosyoekonomik faktörlerin sayısal puan türündeki başarıyı etkilediği sonucuna ulaşmıştır. Kılıç ve Haşıloğlu'nun (2017) çalışması öğrencilerin sosyoekonomik düzeyi ile Türkçe ve Fen Bilimleri dersleri başarı puanları arasında kuvvetli bir ilişkinin bulunduğunu ortaya koymuştur. Özkan'ın (2018) araştırmasında ise evde eğitim olanağı ve kaynağı fazla olan öğrencilerin akademik başarı ortalamasının evde eğitim olanağı ve kaynağı az olan öğrencilere kıyasla daha yüksek olduğu bildirilmiştir. Bu çalışmanın ve alanyazındaki çalışmaların örtüşen sonuçları, ekonomik, sosyal ve kültürel düzeyi iyi olan ailelerin öğrencilerinin akademik açıdan daha başarılı olduğunu raporlamaktadır. Bunun nedenlerinden birisinin Erkan'ın (2011) da dikkat çektiği, ebeveynin eğitim düzeyinin ve sosyoekonomik düzeyinin öğrencilerin hazırbulunuşluk düzeyleri üzerindeki etkisi olabilir. Bir diğer faktör ise Hortaçsu'nun (1995) üzerinde durduğu, kültür düzeyi yüksek ebeveynin çocuklarına öğrenme süreçlerinde daha iyi bir yönlendirme ve rehberlik yapabilmesi olabilir. Bununla birlikte "kültürel sermaye açısından en varlıklı kesimlerin çocuklarının eğitimine yatırım yapma eğiliminde olmaları" (Bourdieu, 1996, s.120) da bir etken olabilir. Ekonomik, sosyal ve kültürel düzeyi iyi olmayan öğrenciler ailelerine destek olmak için bazı eğitimsel taleplerinden vazgeçerken, ekonomik, sosyal ve kültürel düzeyi iyi olan ailelerin çocukları için daha fazla eğitim bütçesi ayırabildikleri Durgun (2011), Sarıer (2010) ve Tomul'un (2007) çalışmalarında ortaya koydukları bir gerçektir. Daha fazla basılı ve çevrimiçi kaynak, özel ders, az mevcutlu sınıflarla ve bire bir etütler ya da hafta sonu kursları gibi destekler sunan özel okullar gibi olanaklar sağlanabilen öğrencilerin bunlardan mahrum kalan öğrencilere kıyasla daha başarılı olmaları genelde beklenen bir durum olduğu ifade edilebilir. 
Türkiye'de ekonomik, sosyal ve kültürel düzeyin akademik başarının yordayıcısı olması bir problem alanı olarak görülebilir. Ekonomik, sosyal ve kültürel açıdan iyi düzeyde olan öğrencilerin eğitimle ilgili sahip oldukları birtakım avantajların ekonomik, sosyal ve kültürel açıdan iyi düzeyde olmayan öğrencilerin aleyhine sonuçlar oluşturduğu söylenebilir (Yaşar, 2016). Ekonomik, sosyal ve kültürel düzeyi düşük ailelerin çocuklarının bu durumu tersine çevirebilmek için sahip oldukları en önemli silah olan eğitim (Wolfe ve Haveman, 2002), bu araştırmanın sonuçlarında görüldüğü gibi Türkiye'de işe yaramayabilir. Çünkü akademik başarısı yüksek olan öğrencilerin okulda kalma sürelerinde dolayısıyla eğitim düzeylerinde bir artış olabilir ve bu da hem işgücüne katılımı artırarak (Saxton, 2000) ekonomik iyileşmeyi hem de sosyalleşme ve kültür düzeyini geliştirebilir. Okullar kültürel sermayenin dağılımının ve sonuç olarak sosyal alanın yapısının yeniden üretilmesine katkıda bulunmaktadır (Bourdieu, 1998). Ancak bu araştırmanın sonuçları da göstermektedir ki Türkiye'de ekonomik, sosyal ve kültürel düzeyi düşük ailelerin çocuklarının akademik başarıları da düşüktür ve bu durumda eğitim, toplum katmanları arasındaki uçurumu kapatmaktan ziyade aranın daha da açılmasına hizmet edebilir. Bu görüş Bourdieu'nun (1987) sosyal farklılaşmadaki temel faktörün, sosyal yapıların inşasında bir kart oyunundaki aslar gibi etkili olabilen ekonomik güç olduğu yönündeki düşünceleriyle de örtüşmektedir.

Bu araştırmanın sınırlılıklarından birisi, Singh, Granville ve Dika (2002)'nın çalışmasında da üzerinde durduğu karmaşık yapıların ölçülmesidir. Öğrencilere ilişkin ekonomik, sosyal ve kültürel düzey ile eudaimonia indeks puanları yüksek güvenirlik ve geçerlik ile belirlenmesi zor olan karmaşık bir değişkendir. PISA-2018' in tasarımında ve uygulanmasında buna yönelik tedbirler olsa bile, bu değişkenlerle ilgili verilerin elde edildiği soru sayısının azlığı, yordayıcılığın güvenilir ve geçerli bir şekilde ölçümünü sınırlayabilir. Bu sınırlılığa rağmen, tüm analiz sonuçlarının istatistiksel olarak anlamlı çıması ve akademik başarı puanları ile ilgili basit doğrusal regresyon analizi sonuçlarının benzerlik göstermesi, yordayıcı değişkenin, öğrencilerin eudaimoniasındaki ve akademik başarılarındaki önemini gösteren teorik modelin sağlamlığını desteklediği söylenebilir.

Özetle, Türkiye' deki 15 yaş grubu öğrencilerin akademik başarıları üzerinde ekonomik, sosyal ve kültürel düzey faktörü anlamlı bir yordayıcıyken, bu dışsal faktörün yaşamın anlamını ve amacını içeren eudaimonia üzerinde anlamlı bir belirleyici olmadığı söylenebilir. Araştırmanın sonuçları doğrultusunda bazı önerilerde bulunulabilir:

1. Akademik başarısızlığının kaynağı düşük ekonomik, sosyal ve kültürel düzey olması muhtemel öğrencilerin belirlenerek, bu öğrencilerin ihtiyacı olan sosyoekonomik ve kültürel desteğin verilmesi, öğretmenlerin ya da ebeveynin tek başlarına üstesinden gelebilecekleri bir durum değildir. Bu yardımın sağlanması, ebeveyn, öğretmenler, okulların psikolojik danışmanlık ve rehberlik servisleri, okul yönetimi, okul aile birliği, sosyal destek kuruluşları gibi öğeleri kapsayan birtakım çalışmasını gerektirebilir. Bu nedenle, okullar kendi içlerinde oluşturacakları bir birimle öğrencilerin ihtiyaç duyduğu desteği eşgüdüm içinde verebilir.

2. Türkiye'deki 15 yaş grubu öğrenciler Türkiye'nin potansiyel gücüdür. Bu açıdan, eğitimcilerin ve politika yapıcıların bu öğrencilerin akademik başarılarını artırmaya yönelik stratejiler geliştirmesi gerektiği söylenebilir. Örneğin, okullar öğrenciyi merkeze alan araştırmalar yoluyla ekonomik, sosyal ve kültürel düzeyi düşük ancak akademik açıdan başarılı olan öğrencileri belirleyebilir ve bu sayede daha fazla sayıda öğrenciye erken okul kademelerinden itibaren devlet ve özel sektör bursu verilebilir. Ayrıca, ekonomik, sosyal ve kültürel düzeyi düşük ailelerin yaşadığı bölgelere daha fazla eğitim yatırımı yapılabilir, sınırlı kaynaklar bu bölgeleri desteklemek için kullanılabilir.

3. Öğrencilerin akademik başarılarını yükseltmek için ailelere ve öğretmenlere, ekonomik, sosyal ve kültürel desteğin öğrencilerin akademik başarılarına olan etkisi konusunu içeren eğitim programları düzenlenebilir. Bu sayede, ailelerin sahip olduğu ekonomik, sosyal ve kültürel varlıkların öğrencilerin eğitimine daha çok yönlendirilmesi sağlanabilir.

4. Ayrıca, tartışma bölümünde belirtilen araştırmanın mevcut sınırlılıkları kapsamında araştırmacılara bazı önerilerde bulunulabilir. Bu bağlamda, gelecekteki araştırmalar, öğrencilerin eudaimonialarını ve 
akademik başarılarını daha fazla açıklayan değişkenleri içerebilir. Bununla birlikte Türkiye'deki öğrencilerin eudaimonialarının ve akademik başarılarının yordayıcılarına dair daha fazla bilimsel kanıt gereklidir ve daha fazla sayıda öğrenci ile analizler yapılması bu konuda daha kesin kanıtlar sağlayabilir. Bu araştırmanın örnekleminin sadece 15 yaşındaki öğrencilerle sınırlı olması, sonuçların diğer okul kademelerindeki öğrenciler için genellenmesini zorlaştırmaktadır. Bundan dolayı araştırmanın farklı okul kademelerinde de yapılmasının öğrencilerin eudaimonia ve akademik başarı düzeylerinin yükseltilmesi konusunda faydalı olacağı düşünülmektedir.

\section{Yazar(lar)ın Beyanı}

Araştırmacıların katkı oranı beyanı: Araştırmacı çalı̧̧manın tümünü kendisi tasarlamış ve tüm aşamalarını kendisi gerçekleştirmiştir.

Çatışma beyanı: Araştırma sürecinde herhangi bir kişi ya da kurumla çıkar çatışması yaşanmamıştır.

Destek ve teşekkür: Araştırma sürecinde herhangi bir kişi ya da kurumdan destek alınmamıştır.

\section{Kaynaklar}

Allison, P. D. (2002). Missing data. Thousand Oaks, CA: Sage Publications, Inc.

Amato, P. R. ve Zuo, J. (1992). Rural poverty, urban poverty, and psychological well-being. The Sociological Quarterly, 33(2), 229-240.

Aslanargun, E., Bozkurt, S. ve Sarığlu, S. (2016). Sosyo ekonomik değişkenlerin öğrencilerin akademik başarısı üzerine etkileri. Uşak Üniversitesi Sosyal Bilimler Dergisi, 9(3), 201-234.

Biswas-Diener, R. ve Dean, B. (2007). Positive psychology coaching putting the ccintific happinessto work for your clients. Hoboken, New Jersey: John Wiley \& Sons, Inc.

Bourdieu, P. (1987). What makes a social class? On the theoretical and practical existence of groups. Berkeley Journal of Sociology, 32, 1-17.

Bourdieu, P. (1996). Distinction: A social critique of the judgement of taste (Çev. Richard Nice). Cambridge, Massachusetts: Harvard University Press.

Bourdieu, P. (1998). Practical reason: On the theory of action. Stanford, California: Stanford University Press.

Cenkseven-Önder, F. ve Sarı, M. (2009). Öğretmenlerde öznel iyi olmanın yordayıcıları olarak okul yaşam kalitesi ve tükenmişlik. Kuram ve Uygulamada Ĕ̆itim Bilimleri, 9(3), 1205-1236.

Clark, A. E., Frijters, P. ve Shields, M. A. (2008). Relative income, happiness, and utility: An explanation for the Easterlin paradox and other puzzles. Journal of Economic literature, 46(1), 95-144.

Collins, J. W. ve O'Brien, N. P. (2003). The Greenwood dictionary of education. Westport: Greenwood Press.

Crespo, R. F. ve Mesurado, B. (2015). Happiness economics, eudaimonia and positive psychology: From happiness economics to flourishing economics. Journal of Happiness Studies, 16(4), 931-946. doi:10.1007/s10902-014-9541-4

Çiftçi, C. ve Çağlar, A. (2014). Ailelerin sosyo ekonomik özelliklerinin öğrenci başarısı üzerindeki etkisi Fakirlik kader midir? International Journal of Human Sciences, 11(2), 155-175. doi:10.14687/ijhs.v11i2.2914

Diener, E., Wirtz, D., Tov, W., Kim-Prieto, C., Choi, D. W., Oishi, S. ve Biswas-Diener, R. (2010). New wellbeing measures: Short scales to assess flourishing and positive and negative feelings. Social indicators research, 97(2), 143-156. doi:10.1007/s11205-009-9493-y

Durgun, Ö. (2011). Türkiye' de yoksulluk ve çocuk yoksulluğu üzerine bir inceleme. Bilgi Ekonomisi ve Yönetimi Dergisi, 6(1), 143-154.

Ehtiyar, R. V., Ersoy, A., Akgün, A. ve Karapınar, E. (2017). Üniversite öğrencilerinin geleceğe yönelik tutum 
ve olumlu gelecek beklentilerinin psikolojik iyilik halleri üzerindeki etkisi. Mediterranean Journal Of Humanities, 7(2), 251-262. doi:10.13114/MJH.2017.361

Erkan, S. (2011). Farklı sosyoekonomik düzeydeki ilköğretim birinci sınıf öğrencilerinin okula hazır bulunuşluklarının incelenmesi. Hacettepe Üniversitesi Ĕ̆itim Fakültesi Dergisi, 40, 186-197.

Gallagher, M. W. (2009) Well-being. S. J. Lopez (Ed.), Encylopedia of positive psychology (s. 1030-1034) içinde. West Sussex: John Wiley and Sons.

Gülcan, A. ve Nedim-Bal, P. (2014). Genç yetişkinlerde iyimserliğin mutluluk ve yaşam doyumu üzerindeki etkisinin incelenmesi. Asya Öğretim Dergisi, 2(1(Özel)), 41-52.

Hajjar, S. T. E. (2018). Statistical analysis: Internal-consistency reliability and construct validity. International Journal of Quantitative and Qualitative Research Methods, 6(1), 46-57.

Hortaçsu, N. (1995). Parents' education levels, parents' beliefs, and child outcomes. The Journal of Genetic Psychology, 156(3), 373-383.

Huta, V. ve Waterman, A. S. (2014). Eudaimonia and its distinction from hedonia: Developing a classification and terminology for understanding conceptual and operational definitions. Journal of Happiness Studies, 15(6), 1425-1456. doi:10.1007/s10902-013-9485-0

Johnston, M. P. (2017). Secondary data analysis: A method of which the time has come. Qualitative and Quantitative Methods in Libraries, 3(3), 619-626.

Kagan, S. (1992). The limits of well-being. Social Philosophy \& Policy, 9(2), 169-189.

Kalaycı, N. (2014). Daimondan eudaimonia'ya: Aristoteles'te mutluluk. Cogito Aristoteles Özel Sayısı, (77), 257274.

Karaağaç, Z. (2019). Ekonomik, sosyal ve kültürel statünün temel eğitimden ortaöğretime geçiş üzerine etkisi (Yayımlanmamış doktora tezi). Yıldırım Beyazıt Üniversitesi, Sosyal Bilimler Enstitüsü, Ankara.

Kasser, T., Cohn, S., Kanner, A. D. ve Ryan, R. M. (2007). Some costs of American corporate capitalism: A psychological exploration of value and goal conflicts. Psychological Inquiry, 18(1), 1-22. doi:10.1080/10478400701386579

Kasser, T. ve Ryan, R. M. (1993). A dark side of the American dream: Correlates of financial success as a central life aspiration. Journal of Personality and Social Psychology, 65(2), 410-422. doi:10.1037/0022-3514.65.2.410

Kenç, M. F. ve Oktay, B. (2002). Akademik benlik kavramı ve akademik başarı arasındaki ilişki. Ĕğitim ve Bilim, 27(124), 71-79.

Kenny, C. (1999). Does growth cause happiness, or does happiness cause growth? Kyklos, 52(1), 3-25.

Khumalo, I. P., Temane, Q. M. ve Wissing, M. P. (2012). Socio-demographic variables, general psychological well-being and the mental health continuum in an African context. Social Indicators Research, 105(3), 419442. doi:10.1007/s11205-010-9777-2

Kılıç, Y. ve Haşıloğlu, M. A. (2017). Sosyoekonomik durumun öğrenci başarısına etkisi (7. Sınıf Türkçe ve fen bilimleri dersleri örneklemi). Yüzüncü Yıl Üniversitesi Eğitim Fakültesi Dergisi, 14(1), 1025-1049.

Klein, C. (2019). Economic freedom and eudaimonic well-being: Exploring the socio-economic paths to psychological functioning (Yayımlanmamiş doktora tezi). Baylor University, Waco, Texas. https://hdl.handle.net/2104/10577 adresinden erişildi.

Kpolovie, P. J., Joe, A. I. ve Okoto, T. (2014). Academic achievement prediction: Role of interest in learning and attitude towards school. International Journal of Humanities Social Sciences and Education (IJHSSE), 1(11), 73100. 
Livan, H. F. (2016). Phronēsis: Aristoteles düşüncesinde etik ve politika ilişkisi (Yayımlanmamış yüksek lisans tezi). Hacettepe Üniversitesi, Sosyal Bilimler Enstitüsü, Ankara.

Lumley, T., Diehr, P., Emerson, S. ve Chen, L. (2002). The importance of the normality assumption in large public health data sets. Annual Review of Public Health, 23(1), 151-169.

Lyubomirsky, S., King, L. ve Diener, E. (2005). The benefits of frequent positive affect: Does happiness lead to success? Psychological Bulletin, 131(6), 803-855. doi:10.1037/0033-2909.131.6.803

Mackenzie, C. S., Karaoylas, E. C. ve Starzyk, K. B. (2018). Lifespan differences in a self determination theory model of eudaimonia: A cross-sectional survey of younger, middle-aged, and older adults. Journal of Happiness Studies, 19(8), 2465-2487. doi:10.1007/s10902-017-9932-4

McGinn, K. (2008). Secondary data. L. M. Given (Ed.), The Sage encyclopedia of qualitative research methods volumes $1 \mathcal{E} 2$ (s. 803-804) içinde. Thousand Oaks, California: SAGE Publications, Inc.

Mirazchiyski, P. (2014). Analyzing the TALIS data using the IEA IDB Analyzer. A. Becker (Ed.), TALIS user guide for the international database (s. 28-72) içinde. Paris: OECD Publishing.

Morgan, J. ve Farsides, T. (2009). Measuring meaning in life. Journal of happiness Studies, 10(2), 197-214. doi:10.1007/s10902-007-9075-0

Myers, D. G. ve Diener, E. (1995). Who is happy? Psychological science, 6(1), 10-19. doi:10.1111/j.14679280.1995.tb00298.x

Omay, N.M. (2004). Aristoteles ahlâkında 'mutluluk' kavramı (Yayımlanmamış yüksek lisans tezi). İstanbul Üniversitesi, Sosyal Bilimler Enstitüsü, İstanbul.

Organisation for Economic Co-operation and Development. (2009). PISA data analysis manual: SPSS (Second Edition). Paris: OECD Publishing

Organisation for Economic Co-operation and Development. (2017). PISA 2015 technical report. Paris: OECD Publishing

Organisation for Economic Co-operation and Development. (2019a). PISA 2018 Assessment and analytical framework. Paris: OECD Publishing. doi:10.1787/b25efab8-en

Organisation for Economic Co-operation and Development. (2019b). PISA 2018 results (Volume III): What school life means for students' lives. Paris: OECD Publishing. doi:10.1787/acd78851-en

Organisation for Economic Co-operation and Development. (2019c). PISA 2018 results (Volume I): What students know and can do. Paris: OECD Publishing. doi:10.1787/5f07c754-en

Özkan, U. B. (2018). TIMSS-2015 sonuçlarının evde bulunan eğitimsel kaynaklar açısından karşılaştırmalı olarak değerlendirilmesi. Amasya Üniversitesi Ĕ̆̆itim Fakültesi Dergisi, 7(1), 98-120.

Peterson, C., Park, N. ve Seligman, M. E. (2005). Orientations to happiness and life satisfaction: The full life versus the empty life. Journal of happiness studies, 6(1), 25-41. doi:10.1007/s10902-004-1278-z

Reker, G. T. (1996). Manual of the sources of meaning profile-revised (SOMP-R). Peterborough: Student Psychologists Press. doi:10.13140/2.1.1617.2802

Reker, G. T. (2000). Theoretical perspectives, dimensions and measurement of existential meaning. G. T. Reker ve K. Chamberlain (Ed.), Exploring existential meaning: Optimising human development acrossthe life span (s. 39-55) içinde. USA: Sage.

Rutkowski, L., Gonzalez, E., Joncas, M. ve von Davier, M. (2010). International large-scale assessment data: Issues in secondary analysis and reporting. Educational Researcher, 39(2), 142-151.

Ryan, R. M. ve Deci, E. L. (2001). On happiness and human potentials: A review of research on hedonic and eudaimonic well-being. Annual Review of Psychology, 52(1), 141-166. 
Ryan, R. M., Huta, V. ve Deci, E. L. (2008). Living well: A self-determination theory perspective on eudaimonia. Journal of Happiness Studies, 9(1), 139-170. doi:10.1007/s10902-006-9023-4

Ryan, R. M. ve Martela, F. (2016). Eudaimonia as a way of living: Connecting Aristotle with self-determination theory. Joar Vittersø (Ed.), Handbook of eudaimonic well-being (s. 109-122) içinde. Cham: Springer. doi:10.1007/978-3-319-42445-3_7

Ryff, C. D. (1989). Happiness is everything, or is it? Explorations on the meaning of psychological well-being. Journal of personality and social psychology, 57(6), 1069-1081.

Ryff, C. D. (1995). Psychological well-being in adult life. Current Directions in Psychological Science, 4(4), 99-104.

Ryff, C. D. (2019). Entrepreneurship and eudaimonic well-being: Five venues for new science. Journal of Business Venturing, 34(4), 646-663.

Ryff, C. D. ve Singer, B. (1998). The contours of positive human health. Psychological Inquiry, 9, 1-28. doi:10.1207/s15327965pli0901_1

Ryff, C. ve Singer, B. (2008). Know themself and become what you are: A eudaimonic approach to psychological well-being. Journal of Happiness Studies, 9, 13-39.

Sarıer, Y. (2010). Ortaöğretime Giriş Sınavları (OKS-SBS) ve PISA sonuçları ışığında eğitimde fırsat eşitliğinin değerlendirilmesi. Ahi Evran Üniversitesi Eğitim Fakültesi Dergisi, 11(3), 107-129.

Saxton, J. (2000). Investment in education: Private and public returns. Washington, DC: Joint Economic Committee.

Shatskikh, S.Y. ve Melkumova, L. E. (2016). Normality assumption in statistical data analysis. Proceedings from ITNT-2016: International Conference Information Technology and Nanotechnology. Samara, Russia: CEURWorkshop. http://ceur-ws.org/Vol-1638/Paper90.pdf adresinden erişildi.

Sherif, V. (2018). Evaluating preexisting qualitative research data for secondary analysis. Forum: Qualitative Social Research, 19(2), 26-42.

Singh, K., Granville, M. ve Dika, S. (2002). Mathematics and science achievement: Effects of motivation, interest, and academic engagement. The journal of educational research, 95(6), 323-332. doi:10.1080/00220670209596607

Sokoya, G. O., Muthukrishna, N. ve Collings, S. J. (2005). Afrocentric and gendered constructions of psychological well-being in Nigeria: A case study. Journal of Psychology in Africa, 15(1), 31-40.

Steger, M. F., Kashdan, T. B., Sullivan, B. A. ve Lorentz, D. (2008). Understanding the search for meaning in life: Personality, cognitive style, and the dynamic between seeking and experiencing meaning. Journal of Personality, 76(2), 199-228.

Streiner, D. L. (2003). Starting at the beginning: an introduction to coefficient alpha and internal consistency. Journal of personality assessment, 80(1), 99-103. doi:10.1207/S15327752JPA8001_18

The Global Council for Happiness and Wellbeing. (2019). Global happiness and wellbeing policy report 2019. New York: Sustainable Development Solutions Network.

Tomul, E. (2007). Türkiye'de eğitime katılım üzerinde gelirin etkisi. Pamukkale Üniversitesi Eğitim Fakültesi Dergisi, 2(22), 122-131.

Turner, P. D. (1997, Mart). Secondary analysis of qualitative data. Annual Meeting of the American Educational Research Association, Chicago, IL, USA. https:/files.eric.ed.gov/fulltext/ED412231.pdf adresinden erişildi.

Vanhoutte, B. ve Nazroo, J. (2016). Life course pathways to later life wellbeing: A comparative study of the role of socio-economic position in England and the US. Journal of population ageing, 9(1-2), 157-177. doi:10.1007/s12062-015-9127-x

Waterman, A. S. (1990). The relevance of Aristotle's conception of eudaimonia for the psychological study of 
happiness. Theoretical \& Philosophical Psychology, 10(1), 39-44.

Waterman, A. S. (1993). Two conceptions of happiness: Contrasts of personal expressiveness (eudaimonia) and hedonic enjoyment. Journal of Personality and Social Psychology, 64(4), 678-691.

Waterman, A. S. (2013). The best within us: Positive psychology perspectives on eudaimonia. Washington DC: American Psychological Association.

Waterman, A. S., Schwartz, S. J. ve Conti, R. (2008). The implications of two conceptions of happiness (hedonic enjoyment and eudaimonia) for the understanding of intrinsic motivation. Journal of Happiness Studies, 9(1), 41-79. doi:10.1007/s10902-006-9020-7

Waterman, A. S., Schwartz, S. J., Zamboanga, B. L., Ravert, R. D., Williams, M. K., Bede Agocha, V., ... Brent Donnellan, M. (2010). The questionnaire for eudaimonic well-being: Psychometric properties, demographic comparisons, and evidence of validity. The Journal of Positive Psychology, 5(1), 41-61. doi:10.1080/17439760903435208

Wolfe, B. ve Haveman, R. (2002). Social and nonmarket benefits from education in an advanced economy. Yolanda K. Kodrzycki (Ed.) Education in the 21st century: Meeting the challenges of a changing world (s. 97142) içinde. Boston: Federal Reserve Bank of Boston.

Yaşar, M. R. (2016). Yoksulluk, akademik başarı ve kültürel sermaye ilişkisi. Journal of Social Sciences/Sosyal Bilimler Dergisi, 6(11), 202-237.

Yolsal, H. (2016). Öğrencilerin sosyo-ekonomik ve kültürel statülerinin PISA 2012 başarıları üzerindeki etkisinin incelenmesi. Sosyal Bilimler Araştırma Dergisi, 5(3), 7-27.

York, T. T., Gibson, C. ve Rankin, S. (2015). Defining and measuring academic success. Practical Assessment, Research, and Evaluation, 20(1), 1-20. doi:10.7275/hz5x-tx03 


\section{EXTENDED ABSTRACT}

\section{Introduction}

One of the two focal points of this study is eudaimonia in the context of the meaning of life. The Organisation for Economic Co-operation and Development (OECD) emphasizes that individuals with a strong eudaimonia are ideal learners and they have a sense of belonging (OECD, 2019a). In the Programme for International Student Assessment (PISA) conducted by the OECD, the eudaimonia index is calculated for each student by asking questions to determine students' eudaimonia levels.

Research suggests that eudaimonia is changing in socio-cultural contexts and influenced by cultural norms (Khumalo, Temane, \& Wissing, 2012; Ryff \& Singer, 1998; Sokoya et al., 2005). However, studies reveal the relationship between socio-economic factors and eudaimonia (Klein, 2019; Mackenzie, Karaoylas, \& Starzyk, 2018; Ryan \& Martela, 2016; Vanhoutte \& Nazroo, 2016). Some researchers argue that academic success is influenced by economic, social, and cultural factors (Aslanargun, Bozkurt, \& Sarioglu, 2016; Ciftci \& Caglar, 2014; Karaagac, 2019; Yolsal, 2016).

The other focus of this research is the academic success of students. Academic success can be considered a result of the quality of academic studies of students, such as course grades or GPA (York, Gibson, \& Rankin, 2015). The most recent PISA, PISA-2018, was conducted in 2018. Students from Turkey were evaluated in mathematics, reading skills, and science.

This study examined the predictive of 15-year-old students' economic, social, and cultural status on students' eudaimonia levels and academic achievement. The study, will first examine whether the economic, social, and cultural status of students on eudaimonia levels are decisive. Then, the predictors of economic, cultural, and social, status of students on their academic achievements will be examined. The research questions are:

1. Is economic, social, and cultural status a significant predictor of students' level of eudaimonia?

2. Is economic, social, and cultural status a significant predictor of students' mathematics, reading skills, and science achievement?

The results of this study will provide important scientific evidence, especially for practitioners and policy makers in the field of education. There are no studies in the literature evaluating the relationship between economic, social, and cultural status within the framework of PISA-2018 and students' eudaimonia levels and academic achievements within the same study. Examining the impact of the economic, social, and cultural status on eudaimonia and academic achievement of students, who will become adults of the future, is very important for Turkey to further its aims of prosperity and happiness for its people.

\section{Method}

This study is a quantitative research and secondary data related to PISA-2018 evaluation were analyzed. The data of this study was obtained from 6890 Turkish students, all aged 15 years, who attended PISA-2018. These students' eudaimonia indices, economic, social, and cultural status indices, and mathematics, reading skills, and science scores were used. The data were analyzed using simple linear regression in the IEA International Database Analyzer Version 4.0.35 (IDB Analyzer) software.

\section{Results}

In answer to the first research question, the simple linear regression analysis results reveal that students' economic, social, and cultural status variables do not contribute to explaining the variation of eudaimonia levels $\left(\mathrm{R}^{2}=.00\right)$. However, the regression coefficients indicate that students' economic, social, and cultural status may result in a rather low increase (.03) in eudaimonia levels.

The simple linear regression analysis results to answer the second research question revealed that students' economic, social, and cultural status variables explained $11 \%$ of the variation $\left(\mathrm{R}^{2}=.11\right)$ in mathematics, reading skills, and science achievement scores. Economic, social, and cultural status as a 
predictor are statistically significant. However, regression coefficients show that students' economic, social, and cultural status may increase students' mathematics, reading skills, and science scores $\left(B_{\text {math }}=25.07\right.$, $B_{\text {literacy }}=25.01, B_{\text {science }}=23.43$ ).

\section{Conclusion}

The results of this study demonstrate that economic, social, and cultural status of students in Turkey does not change the subjects' level of eudaimonia. However, it was concluded that the economic, social, and cultural status is a significant predictor of mathematics, reading skills, and science achievement. While economic, social, and cultural status factors are a significant predictor of academic achievement of 15-year-old students in Turkey, it can be said that this external factor is not a significant determinant of eudaimonia, which more broadly includes the meaning and purpose of life. Despite some limitations of the research, as all the analysis results are statistically significant and the achievement scores are similar, it can be said that the predictive variable supports the robustness of the theoretical model that shows the importance of the students' eudaimonia and academic achievements. Accordingly, some suggestions have been made for practitioners and researchers. 